\title{
Estimating seasonal abundance of a central place forager using counts and telemetry data
}

\author{
Ruth J. Sharples ${ }^{1,3, *}$, Monique L. Mackenzie ${ }^{2}$, Philip S. Hammond ${ }^{1}$ \\ ${ }^{1}$ Sea Mammal Research Unit, Gatty Marine Laboratory, University of St Andrews, St Andrews, Fife KY16 8LB, UK \\ ${ }^{2}$ Centre for Research into Ecological and Environmental Modelling, The Observatory, Buchanan Gardens, \\ University of St Andrews, St Andrews, Fife KY16 9LZ, UK
}

${ }^{3}$ Present address: Commonwealth Industrial and Scientific Research Association (CSIRO) Marine and Atmospheric Research, GPO Box 1538, Hobart, Tasmania 7001, Australia

\begin{abstract}
Obtaining population estimates of species that are not easily observed directly can be problematic. However, central place foragers can often be observed some of the time, e.g. when seals are hauled out. In these instances, population estimates can be derived from counts, combined with information on the proportion of time that animals can be observed. We present a modelling framework to estimate seasonal absolute abundance using counts and information from satellite telemetry data. The method was tested on a harbour seal population in an area of southeast Scotland. Counts were made monthly, between November 2001 and June 2003, when seals were hauled out on land and were corrected for the proportion of time the seals were at sea using satellite telemetry. Harbour seals $(n=25)$ were tagged with satellite relay data loggers between November 2001 and March 2003. To estimate the proportion of time spent hauled out, time at sea on foraging trips was modelled separately from haul-out behaviour close to haul-out sites because of the different factors affecting these processes. A generalised linear mixed model framework was developed to capture the longitudinal nature of the data and the repeated measures across individuals. Despite seasonal variability in the number of seals counted at haul-out sites, the model generated estimates of abundance, with an overall mean of 846 (95\% CI: 767 to 979). The methodology shows the value of using count and telemetry data collected concurrently for estimating absolute abundance, information that is essential to assess interactions between predators, fish stocks and fisheries.
\end{abstract}

KEY WORDS: Mixed effects models $\cdot$ Phoca vitulina $\cdot$ Population size $\cdot$ Autocorrelation $\cdot$ Harbour seal $\cdot$ Haul-out behaviour $\cdot$ Central place forager

\section{INTRODUCTION}

The role of top marine predators in influencing marine ecosystem dynamics is increasingly being recognised (Yodzis 2001, Springer et al. 2003, Myers et al. 2007). Simultaneously, the potential for competition between predators and fisheries has raised concerns over the effect of stock declines on top predator populations (DeMaster et al. 2001, Yodzis 2001). The North Sea is among the most heavily exploited shelf seas (Heath 2005) but also supports a variety of cetaceans, seabirds and pinnipeds. Pinniped diet composition substantially overlaps with commercially exploited species in this area (e.g. Harwood \& Croxall 1988, Prime \&
Hammond 1990, Brown \& Pierce 1998). One particular pinniped species of current concern in the North Sea is the harbour seal Phoca vitulina. Sparse counts of pinnipeds have estimated a significant decline in harbour seals from 2000 to the present in a number of populations around Britain (Lonergan et al. 2007).

To accurately assess the consumption of a predator population, absolute population estimates are a far more useful management input than relative abundance indices. However, because many pinnipeds are central place foragers, reliant on land for resting, evading predators, feeding young and moulting, only a proportion of the population is available to be counted at any one time. Estimating the proportion of the popula- 
tion at sea accessing food resources is therefore critical in estimating absolute population size.

Monitoring harbour seal populations across large spatial scales is achieved through aerial photography of haul-out sites during the moult or breeding season when the highest, most consistent numbers of seals are ashore (Duck \& Thompson 2003, Thompson et al. 2005). Counts are variable as the number ashore varies with season (Thompson et al. 1989, Simpkins et al. 2003), tidal state and height (Schneider \& Payne 1983), time of day (Thompson et al. 1989) and prevailing weather conditions (Watts 1992, Grellier et al. 1996) and because there may be only a single count per year. In addition, the component of the population available to be counted on land may not be representative of the age and sex structure of the whole population (Härkönen et al. 1999). Unless these sources of variability can be eliminated or accounted for, the use of minimum numbers counted ashore to infer population size and trends may not provide sufficiently robust information. Conducting 1 count at a fixed date may not capture peak numbers, and a progressive shift in the time of moult, for example, may appear as a population change.

To account for seals that are at sea when counts at haul-out sites are made, dedicated telemetry studies

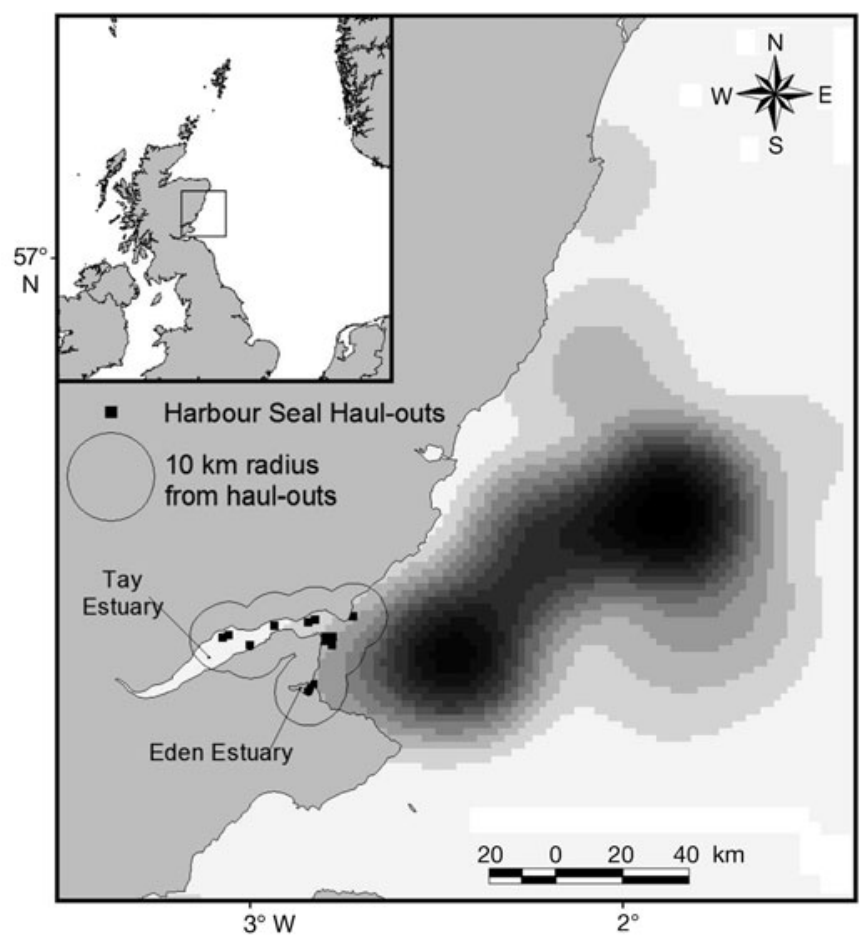

Fig. 1. Locations of the main harbour seal haul-out sites in St Andrews Bay with $10 \mathrm{~km}$ radius displayed. A graduated kernel is displayed of slow at-sea movement locations (speed $<0.5 \mathrm{~m} \mathrm{~s}^{-1}$; thought to be associated with foraging behaviour) not associated with haul-outs. Each shade represents a different $5 \%$ kernel; shade darkens with reduced kernel percentage have been conducted during the pupping season when animals spend more time ashore (Thompson \& Rothery 1987, Thompson \& Harwood 1990, Thompson et al. 1997, Ries et al. 1998, Huber et al. 2001). The pupping season is closely followed by the moult, when transmitters are lost, so data are typically collected for only a short period, making corrections of counts during the moult problematic.

The population of harbour seals selected for this study was in southeast Scotland in a designated Special Area of Conservation (SAC) for this species. The size of the population of harbour seals using this area is of interest not only due to their conservation status but because of the numerous fisheries overlaps that have been identified (Sharples 2005).

Telemetry data are collected on many species of pinnipeds all over the world throughout the year to investigate at-sea distribution and foraging habitat. Our aim was to develop and apply a method to use such data in the estimation of population size, thus providing added value.

The method we developed here uses telemetry and count data collected throughout the year to estimate the proportion of a seal population hauled-out on land, and thus to estimate population size by extrapolating from counts made at haul-out sites using individual activity patterns recorded via satellite relay data loggers (SRDLs).

\section{MATERIALS AND METHODS}

Haul-out counts. Fourteen areas were used by harbour seals as haul-out sites in the study area; the main areas were the Tay and Eden estuaries (Fig. 1). All haul-out sites were intertidal sand banks. Counts were boat-based, and all haul-outs were visited within $\pm 2 \mathrm{~h}$ of low tide. Seals were counted using $7 \times 50$ binoculars at a distance sufficient to obtain an accurate count without disturbing the animals (approximately $200 \mathrm{~m}$ ). Counting numbers of seals by boat was feasible in this area due to the relatively small group sizes and the steep gradient of the sandbanks. Counts of all haul-out areas were attempted at least monthly, although weather conditions prohibited this in 2 mo of the study period.

Transmitters and deployment. SRDLs consisted of a data logger interfaced to an Argos transmitter unit and a depth and submergence sensor (http://www.smru. st-and.ac.uk/Instrumentation/pageset.aspx?psr=286). The SRDL (Sea Mammal Research Unit, St Andrews) measured $100 \times 70 \times 45 \mathrm{~mm}$ (excluding the $150 \mathrm{~mm}$ antenna) and weighed $305 \mathrm{~g}$. The SRDLs collected, compressed and transmitted data via the Argos system; a detailed description is given by McConnell et al. (1992). 
The seals were caught using a $120 \mathrm{~m}$ net, set from a boat around the haul-out site. The net formed a barrier within which seals were trapped as they fled to the water (Jefferies et al. 1993). The net was hauled to shore, and animals were transferred to hoop nets until drugged. Twenty-five harbour seals were tagged in this study, consisting of approximately a 50:50 male:female sample, greater than $50 \mathrm{~kg}$ in size. Seals were weighed and then anaesthetised using $0.05 \mathrm{ml}$ of zoletil per $10 \mathrm{~kg}$ delivered intravenously (Baker et al. 1990).

SRDLs were attached to the fur on the neck of the seal at the base of the skull using a fast setting 2-part epoxy adhesive (Fedak et al. 1983). Seal capture and handling was conducted under the terms of licences issued by the Home Office under the Animals (Scientific Procedures) Act 1986 and the Scottish Executive under the Conservation of Seals Act 1970.

Telemetry data processing and seal activity. Locations were assigned an index of accuracy, termed location quality (LQ), which depends upon the number of uplinks to the satellites within a pass (McConnell et al. 1992). LQ $=3$ denotes the highest accuracy (approximately $226 \mathrm{~m}$, Vincent et al. 2002), LQ = 2 is accurate to $372 \mathrm{~m}, \mathrm{LQ}=1$ is accurate to $757 \mathrm{~m}$ (Vincent et al. 2002) and $\mathrm{LQ}=0$ provides no guarantee of accuracy. Locations with a large degree of error were excluded with an iterative forwards/backwards averaging filter (McConnell et al. 1992).

A seal was classified as being near a haul-out site, or 'within range', when it was within $10 \mathrm{~km}$ of a haul-out site. The distance of $10 \mathrm{~km}$ was chosen to include haulout sites and the surrounding area used between them while excluding foraging areas that appeared to begin $>20 \mathrm{~km}$ from haul-out sites (Sharples 2005). Fig. 1 illustrates the $10 \mathrm{~km}$ radius around the haul-outs as well as a kernel smooth of the slow at-sea movements $(<0.5 \mathrm{~m}$ $\mathrm{s}^{-1}$ ) thought to be associated with foraging behaviour (McConnell et al. 1999). Locations associated with hauling out were not included in this smooth. The dense (darker) areas illustrate the areas thought to be used most for foraging. Due to the varying qualities of location fixes, a seal was deemed to be within $10 \mathrm{~km}$ of the haul-out if either a location fix within the $10 \mathrm{~km}$ was $L Q \geq 1$, or 3 consecutive poor locations ( $L Q<1$ ) occurred within $10 \mathrm{~km}$. In this instance, the time of the first 3 locations was taken to represent the start of a period near the haul-out. The same rules were used to record the departure of an individual from the $10 \mathrm{~km}$ radius.

The activity of each seal was classified into 3 different categories using the following rules: if the tag was dry (i.e. not submerged) for more than $10 \mathrm{~min}$ it was classified as 'hauled-out'; a haul-out period was determined to have ended when the tag became wet or sub- merged for a minimum of $16 \mathrm{~s}$ and at a depth greater than $2 \mathrm{~m}$. Otherwise, at depths greater than $2 \mathrm{~m}$, a seal was classified as 'diving' and at depths less than $2 \mathrm{~m}$, it was classified as 'at the surface'. Data were recorded by the SRDLs providing information on the time a seal spent at the surface, diving or hauled-out throughout any given $2 \mathrm{~h}$ time period. Data were stored and transmitted at random to prevent bias in the data received.

Analysis. Analysis framework: The behaviour of tagged seals suggests that 2 different processes at 2 time scales affect haul-out behaviour. Seals made prolonged foraging trips averaging approximately $6 \mathrm{~d}$ (SE $=0.39 \mathrm{~d}, \mathrm{n}=24$ ) interspersed with shorter periods close to the haul-out site (Sharples 2005). When close to a haul-out site, a seal could be hauled out and thus available to be counted or in the water and unavailable. The covariates that may be expected to explain haul-out behaviour include tidal cycle, time of day and season. However, such short scale factors are unlikely to explain why an individual remains at sea foraging offshore for a prolonged period; within and between year variation are more likely to influence this. These processes lead logically to a framework for analysis incorporating 2 stages: a first stage that models the proportion of time spent close to haul-out sites ('within-range model') and a second stage that models the proportion of time hauled out on land ('haul-out model') when within a given distance of haul-out sites.

The within-range model: The probability of being within $10 \mathrm{~km}$ of a haul-out area was modelled using a generalised linear mixed model (GLMM) with binomial errors. This model framework uses repeated measures from individuals to make inferences about a wider population of individuals. GLMMs also naturally accommodate within-individual correlation. For instance, observations within individuals over time tend to be more similar than observations from different individuals, and ignoring this positive correlation may result in unrealistically small p-values and/or unnecessary covariates being deemed important. For this reason, accommodating non-independence was considered necessary.

A binomial response was used to indicate if an animal was within a $10 \mathrm{~km}$ radius of a haul-out, and the data were summarised on a monthly basis to give a proportion of time within range. Of the covariates available, month and year were the only variables operating on the time scale appropriate for foraging trips and thus finer scale variables (such as time of day and tide height) were not considered in this model. Month and year were fitted as factor variables in the model, and a month-year interaction effect was also considered for inclusion. The Akaike information criterion (AIC) statistic was used to choose between models containing different covariates. The intercept parame- 
ter was permitted to vary randomly across individuals (as a random effect term) and an AR(1) auto-correlation error structure was also trialled for inclusion in the model. An AR(1) structure assumes that haul-out measurements within individuals and closest together in time are most highly correlated and that this correlation decays with time. This AR(1) structure was chosen by examining correlograms for the working residuals. Extra-binomial dispersion was also permitted via estimation of a dispersion parameter.

Parameter estimation was first carried out using numerical integration via the NLMIXED procedure in SAS to allow AIC selection for model covariates. A restricted pseudo-likelihood (REPL)-based fitting procedure was then used on the selected model to test for any residual auto-correlation and to estimate any extra-binomial dispersion (using the GLIMMIX macro in SAS). Retention of the AR(1) error structure was based on the p-value associated with the AR(1) correlation coefficient.

The haul-out model: The probability of an animal hauling out in each $2 \mathrm{~h}$ period was also modelled using a GLMM with binomial errors. A binary response was used to indicate an animal's haul-out behaviour for a given $2 \mathrm{~h}$ period; if the animal was hauled out for more than $1 \mathrm{~h}$ during a $2 \mathrm{~h}$ period it was assigned a value of 1 , and if the animal was in the water for more than $1 \mathrm{~h}$ during this time it was assigned a 0 . This binary outcome adequately summarised the data; the animals tended to spend either all or little of each $2 \mathrm{~h}$ period hauled-out.

Five covariates were considered in the model: time of day, tide height (in m), state of tide, month and year. Since time of day is a circular statistic, a periodic spline (Wood 2006) with equally spaced knots was used to model 'hour' $(h)$ to ensure predictions are equal at 0 and $24 \mathrm{~h}$. The flexibility of this spline was chosen using the AIC statistic at every stage of the selection process. State of tide was assigned a 0 value for a falling tide and 1 for a rising tide. Month was considered as a factor in the model for maximum flexibility.

The data consisted of haul-out observations from individuals, from two 8 mo study seasons, and thus a GLMM framework was appropriate. The intercept parameter was permitted to vary randomly across individuals (as a random effect term) while the residual correlation within individuals was assumed to exhibit an $\mathrm{AR}(1)$ structure. A dispersion parameter was also estimated.

Model covariates were chosen using backwards selection commencing with a 5 covariate model. The AIC statistic was used to govern initial model selection; however, evidence for covariate relationships was also assessed using model p-values. Interaction effects were also considered for inclusion in the model. Likeli- hood ratio tests were used to return a single $\mathrm{p}$-value for factor variables with many levels (e.g. month).

Combining the within-range and haul-out models: The probability that an animal was both within $10 \mathrm{~km}$ of a haul-out area and hauled out was estimated using the 'haul-out' and the 'within-range' models. Specifically, given a set of covariate values for each haul-out count, the estimated probability that an animal was within range and hauled out was obtained by multiplying the predicted probability that an animal was within range with the predicted probability that an animal was hauled out. These mixed model probabilities were obtained by averaging over 10000 re-samples from the normal random effects distribution based on REPL procedure variance estimates.

Estimates of population abundance: A population estimate at a particular time point $\left(\hat{N}_{t}\right)$ based on the estimated probabilities of being within range and hauled out and the observed counts at haul-out sites was then obtained using:

$$
\hat{N}_{t}=\frac{n_{t}}{\hat{p}_{(H O / W R), t} \times p_{(W R), t}}
$$

where $\hat{N}_{t}=$ estimated population size at time $t_{i} n_{t}=$ number of seals counted at haul-outs at time $t_{i} \hat{p}_{(W R), t}=$ estimated probability of being within $10 \mathrm{~km}$ of a haulout site at time $t$ (during month $m) ; \hat{p}_{(H O / W R), t}=$ estimated probability of being hauled out, conditional on being within $10 \mathrm{~km}$ of a haul-out site at time $t$.

Modelling uncertainty in population estimates: The uncertainty in $\hat{N}_{t}$ was obtained using a parametric bootstrap approach based on model variance estimates for both the within-range and haul-out models. Specifically, the fixed and random effect bootstrap coefficients were repeatedly harvested from a (multivariate) normal distribution with REPL-based variancecovariance estimates. These random realisations gave bootstrap estimates for each probability in the above equation and combined with the observed counts at each time point to give a set of bootstrap population estimates. The mean population estimate at each observed count was also harvested for each bootstrap replicate, and the central $95 \%$ of these estimates was used to derive upper and lower confidence bounds for the mean value across observation times.

This parametric bootstrap technique assumes multivariate normality of the fixed effects, which relies on large sample properties. This assumption may be questionable in this case given that only 24 individuals gave rise to 119 within-range proportions and 11343 haul-out binary observations. To avoid this assumption, a non-parametric bootstrap could have been used instead but this was not expected to yield better estimates of variance based on re-sampling of just 24 individuals. For this reason, the uncertainty about the pop- 
ulation estimates we have reported may be unreliable and the validity of these estimates could only be verified with additional tagged individuals.

\section{RESULTS}

\section{Counts of seals ashore}

A seasonal pattern was observed in the numbers of animals counted at haul-out sites in St Andrews Bay; numbers were lower in winter and higher in summer around the pupping and moulting seasons (Fig. 2). Some inter-annual variability was overlaid on this pattern.

\section{Transmitter performance}

We tagged 25 seals: 13 males and 12 females. The sample included subadult and adult animals, with a weight range of 50 to $92 \mathrm{~kg}$ (Table 1); seals weighing less than $50 \mathrm{~kg}$ were not tagged because of concern about the possible effects of increased drag and weight of the SRDLs on the behaviour of small animals (see 'Discussion'). The majority of animals caught in nets were tagged, and $<10 \%$ were released without tags because they were under $50 \mathrm{~kg}$ or because we had tagged sufficient numbers of that sex for the study. SRDLs transmitted for an average of $131 \mathrm{~d}$ (SE $=6.0 \mathrm{~d}$, range 86 to $202 \mathrm{~d} \mathrm{seal}^{-1}$ ), for a total of $3282 \mathrm{~d}$ (Table 1).

Ten seals were tracked in 2001-2002 and 15 in 2002-2003 (Table 1). In the first study period (Novem- ber 2001 to July 2002), very few of the tags deployed in November and January were still transmitting by June and July. As a result, the tagging period was staggered for the second study period with deployments in November, January and March. This greatly increased the sample of animals tracked through into June and July as shown in Table 1 . No animals were tracked in the months of August, September and October, the period around the annual moult. The percent summary data received from each seal ranged between $63 \%$ and $98 \%($ mean $=84 \%, \mathrm{SE}=1.8 \%)$.

\section{The within-range model}

The overall observed proportion of time spent within $10 \mathrm{~km}$ of haul-out sites averaged over all seals for November through to June for both years was 0.39 (95\% CI $=0.34$ to 0.45$)$. There was compelling evidence for a month-year interaction effect $(p=0.0495)$ but no evidence for residual autocorrelation within seals over time $(\hat{\rho}=0.058, p=0.7225)$; therefore, the AR(1) term was omitted from this model. The predicted proportions of time spent within a $10 \mathrm{~km}$ radius of haul-out sites between November and June exhibited a decline from November to December and then remained stable through to April before increasing until June (Fig. 3). Estimated time spent within range was lowest in December and highest in June, although confidence intervals were wide for all months (Fig. 3). The extra-binomial dispersion parameter estimate was high (19.7977) for this model, and model standard errors were adjusted accordingly.

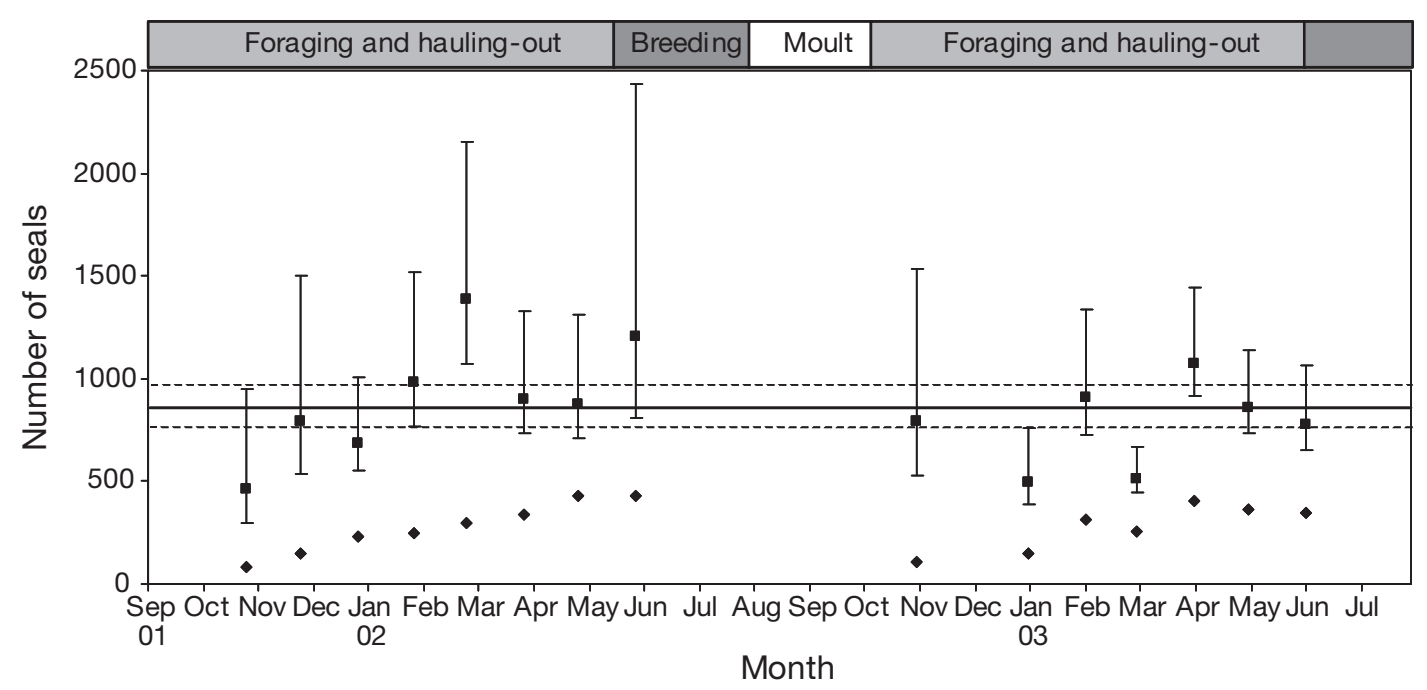

Fig. 2. Phoca vitulina. Population estimates (匹) with $95 \%$ confidence intervals (error bars) compared to counts made at haul-out sites $(\bullet)$. Solid line gives the mean population estimate and dotted lines are the $95 \%$ confidence intervals 
Table 1. Phoca vitulina. Details of tagged seals and tracking periods

\begin{tabular}{|c|c|c|c|c|c|c|c|}
\hline Seal & Sex & $\begin{array}{l}\text { Weight } \\
(\mathrm{kg})\end{array}$ & $\begin{array}{l}\text { Girth } \\
(\mathrm{cm})\end{array}$ & $\begin{array}{l}\text { Length } \\
\text { (cm) }\end{array}$ & $\begin{array}{l}\text { Date of } \\
\text { capture }\end{array}$ & $\begin{array}{l}\text { Date of last } \\
\text { transmission }\end{array}$ & $\begin{array}{l}\text { Duration of } \\
\text { tracking (d) }\end{array}$ \\
\hline A & $\mathrm{M}$ & 68 & 90 & 138 & 02 Nov 01 & 17 Apr 02 & 166 \\
\hline B & M & 69 & 87 & 144 & 02 Nov 01 & 27 Jan 02 & 86 \\
\hline $\mathrm{C}$ & M & 76 & 112 & 142 & 19 Nov 01 & 23 Mar 02 & 124 \\
\hline $\mathrm{D}^{\mathrm{a}}$ & M & 51 & 94 & 125 & 20 Nov 01 & 26 Apr 02 & 157 \\
\hline E & $\mathrm{F}$ & 66 & 102 & 137 & 16 Jan 02 & 21 Jun 02 & 156 \\
\hline $\mathrm{F}$ & M & 59 & 99 & 125 & 16 Jan 02 & 19 May 02 & 123 \\
\hline $\mathrm{G}$ & $\mathrm{F}$ & 82 & 106 & 144 & 16 Jan 02 & 02 May 02 & 106 \\
\hline $\mathrm{H}$ & $\mathrm{F}$ & 76 & 108 & 145 & 16 Jan 02 & 01 May 02 & 105 \\
\hline I & $\mathrm{F}$ & 75 & 108 & 137 & 16 Jan 02 & 26 May 02 & 129 \\
\hline $\mathrm{J}$ & $\mathrm{F}$ & 72 & 101 & 142 & 16 Jan 02 & 06 Aug 02 & 202 \\
\hline K & $\mathrm{F}$ & 50 & 85 & 121 & 24 Oct 02 & 26 Apr 03 & 184 \\
\hline $\mathrm{L}$ & M & 64 & 97 & 136 & 24 Oct 02 & 20 Feb 03 & 119 \\
\hline M & M & 88 & 110 & 143 & 24 Oct 02 & 04 Mar 03 & 131 \\
\hline $\mathrm{N}$ & M & 71 & 102 & 141 & 24 Oct 02 & 07 Mar 03 & 134 \\
\hline $\mathrm{O}$ & M & 78 & 101 & 143 & 24 Oct 02 & 23 Mar 03 & 150 \\
\hline $\mathrm{P}$ & M & 77 & 96 & 132 & 24 Jan 03 & $01 \mathrm{Jul} 03$ & 158 \\
\hline $\mathrm{Q}$ & M & 87 & 104 & 126 & 24 Jan 03 & 04 Jun 03 & 158 \\
\hline $\mathrm{R}$ & $\mathrm{F}$ & 52 & 90 & 123 & 11 Mar 03 & $22 \mathrm{Jul} 03$ & 133 \\
\hline $\mathrm{S}$ & $\mathrm{F}$ & 67 & 96 & 135 & 11 Mar 03 & 22 Jul 03 & 133 \\
\hline $\mathrm{T}$ & $\mathrm{M}$ & 52 & 91 & 120 & 11 Mar 03 & 08 Jun 03 & 89 \\
\hline $\mathrm{U}$ & $\mathrm{F}$ & 75 & 109 & 127 & 11 Mar 03 & $18 \mathrm{Jul} 03$ & 129 \\
\hline $\mathrm{V}$ & $\mathrm{M}$ & 82 & 106 & 138 & 11 Mar 03 & 14 Jun 03 & 95 \\
\hline W & $\mathrm{F}$ & 92 & 111 & 134 & 25 Mar 03 & 27 Jul 03 & 124 \\
\hline $\mathrm{X}$ & $\mathrm{F}$ & 72 & 110 & 131 & 25 Mar 03 & 07 Jul 03 & 104 \\
\hline $\mathrm{Y}$ & $\mathrm{F}$ & 64 & 96 & 139 & 25 Mar 03 & 21 Jun 03 & 87 \\
\hline
\end{tabular}

\section{The haul-out model}

From the saturated model with year-based interactions, only tide height, month and hour were retained in the model; all were significant (Table 2). Two (equally spaced) interior knots were chosen for the periodic spline, since additional curve complexity resulted in higher AIC scores. There was strong evidence for positive within-seal autocorrelation $(\hat{\rho}=$ 0.339; $\mathrm{p}<0.0001$ ); however, there was no evidence for a year effect $(p=0.671)$. While AIC selection would suggest that state should be retained in the model, the high uncertainty (and associated p-value) corresponding to the state parameter meant this was omitted from the model (Table 3). Year-based interaction terms trialled for inclusion were not retained in the model due to their AIC values or the high p-values that resulted (Table 3).

Under the model, the probability of hauling out (conditional on being within $10 \mathrm{~km}$ of a haul-out site) increased as tide height decreased (Fig. 4); animals use sandbanks as haul-out sites, and in this area sandbanks generally only become exposed as tide height drops. The model also predicted hauling out to be least frequent in the winter months (November,
December and January), while the remaining months of the study were predicted to have higher (and similar) haul-out probabilities (Fig. 3). Seals were more likely to haul out around midday in all months, although this trend was less pronounced in the winter months of November, December and January (Fig. 5).

Table 2. Coefficients, standard errors and significance of covariates and factors included in the final GLMM to model the proportion of time hauled out when within $10 \mathrm{~km}$ of a haul-out site

\begin{tabular}{|lrrr|}
\hline Explanatory variable & Coefficient & SE & $p$ \\
\hline Height of tide & -1.065 & 0.021 & $<0.001$ \\
Hour 12 & 0.262 & 0.054 & $<0.001$ \\
Hour 22 & 0.162 & 0.064 & $<0.011$ \\
November & -1.888 & 0.337 & $<0.001$ \\
December & -1.011 & 0.330 & 0.002 \\
January & -0.721 & 0.304. & 0.018 \\
February & 0.017 & 0.303 & 0.955 \\
March & -0.274 & 0.290 & 0.345 \\
April & -0.095 & 0.283 & 0.738 \\
May & -0.302 & 0.285 & 0.288 \\
June & -0.007 & 0.286 & 0.980 \\
\hline
\end{tabular}




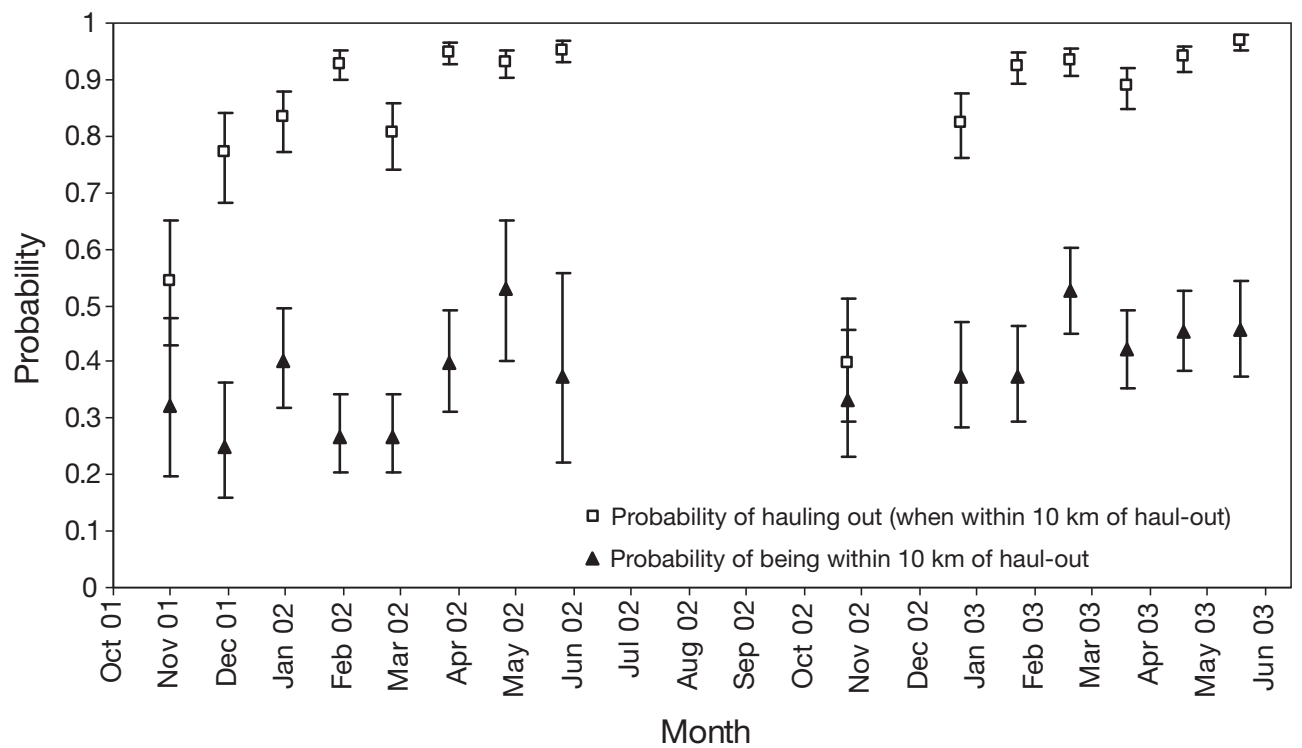

Fig. 3. Phoca vitulina. Estimated probabilities of the proportion of time seals spent within $10 \mathrm{~km}$ of haul-out sites and of the proportion of time seals spent hauled out (when within $10 \mathrm{~km}$ of haul-out sites) per month with $95 \%$ confidence intervals

Table 3. Model selection results for the GLMM-based haul-out model. The full model (FM) has 'Month' fitted as a factor and 'Hour' fitted as a periodic spline with 2 interior knots, AIC = 11294 and 15 parameters in total. Where more than 1 parameter is associated with including a covariate, the likelihood ratio test p-value (assuming independent errors) and the smallest REPLbased $\mathrm{p}$-value (allowing for correlated errors) for the collection of parameters is shown

\begin{tabular}{|c|c|c|c|c|}
\hline Model & AIC & $\mathrm{p}$ & $\begin{array}{l}\text { Change in AIC } \\
\text { compared to FM }\end{array}$ & Parameters \\
\hline \multicolumn{5}{|l|}{ Full model: } \\
\hline FM: Year, State, Month, Height, Hour & 11294 & - & - & 15 \\
\hline FM without Year & 11292 & 0.671 & -2 & 14 \\
\hline FM without State & 11297 & 0.2692 & 3 & 14 \\
\hline FM without Month & 11513 & LRT: $<0.0001$; individual: $<0.0001$ & 219 & 7 \\
\hline FM without Height & 14375 & $<0.0001$ & 3081 & 14 \\
\hline FM without Hour & 11344 & $<0.0001$ & 50 & 13 \\
\hline FM with Month $\times$ Year interaction & 11221 & (LRT) $<0.0001$, individual: $>0.9809$ & -73 & 31 \\
\hline FM with State $\times$ Year interaction & 11305 & 0.8177 & 11 & 16 \\
\hline FM with Hour $\times$ Year interaction & 11298 & $0.4096,0.0118$ & 4 & 16 \\
\hline FM with Height $\times$ Year interaction & 11300 & 0.2000 & 6 & 17 \\
\hline
\end{tabular}

\section{Estimates of population abundance}

Estimates of abundance are shown in Fig. 2, together with raw count data. Despite the 5-fold variation in the counts, the population estimates were consistent. Although estimated abundance varied from approximately 460 to 1383, considering the estimated variability there was no compelling trend during the study period (Fig. 2). November 2001 and January and March 2003 were low relative to the mean population estimate; this may be due in part to lower numbers of seals being tagged at this time (Table 1 ). In addition to this, some of the counts appear uncharacteristically low for the time of year, possibly due to haul-outs being disturbed prior to counts.

The uncertainty in population abundance was particularly high in November (for both years) because fewer animals were tracked, and the behaviour of the tracked seals was markedly more variable in this month in both models. High uncertainty in June 2002 is also likely to be due to low sample sizes and because this was during the breeding season, when males and females behaved considerably differently. The most recent population estimate, in June 2003, was 775 seals (95\% CI: 655 to 947). The mean population estimate over the study period was 846 (95\% CI: 767 to 979; Fig. 2). 


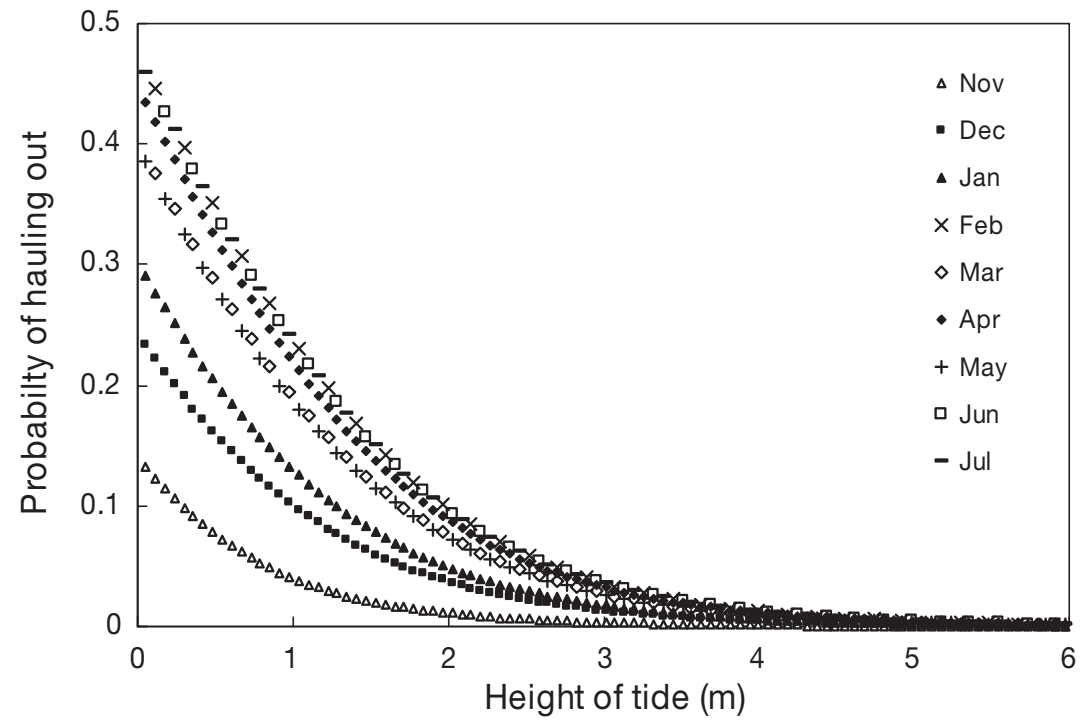

Fig. 4. Phoca vitulina. Estimated probability of hauling out as a function of tide height, by month

population foraging in the area that can be used to estimate annual consumption of prey, including commercial fish stocks.

Abundance estimates were on average $37 \%$ greater than moult counts made here by boat and aerial surveys (Duck \& Thompson 2003). This is comparable to findings from the Moray Firth, northeast Scotland, and the Netherlands, where approximately two-thirds of the harbour seal population was estimated to be hauled out during the pupping and moulting season (Thompson et al. 1997, Ries et al. 1998).

Using satellite telemetry data solely for estimating population size may not be cost effective. However, satellite telemetry is now commonly used around the world to study many aspects of the ecology of marine preda-

\section{DISCUSSION}

Population size estimated from the proportion of the population that is directly observed is subject to bias that can arise in the observable component of the population and as a result of unaccounted for seasonal variation and in environmental conditions (Schneider \& Payne 1983, Thompson et al. 1989, Grellier et al. 1996, Simpkins et al. 2003). Correcting for the proportion of the population at sea in pinnipeds has always been problematic because the time when the highest proportion is ashore is during the breeding and moulting periods when there are known to be age and sex differences in haul-out behaviour (Thompson \& Rothery 1987, Thompson et al. 1989, Härkönen et al. 1999). Nevertheless, our model yielded stable estimates of harbour seal population size throughout the year, outside the breeding and moulting period.

The abundance estimates were consistent across seasons over the 2 study seasons and showed no obvious trend despite the large variation in the observed number of seals hauled-out. The lack of seasonal trend in estimated absolute population size demonstrates that changes in the number hauled-out resulted from seasonal variation in the proportion at sea, rather than seasonal movements of animals to and from other areas. The model therefore provides a valid single estimate of the

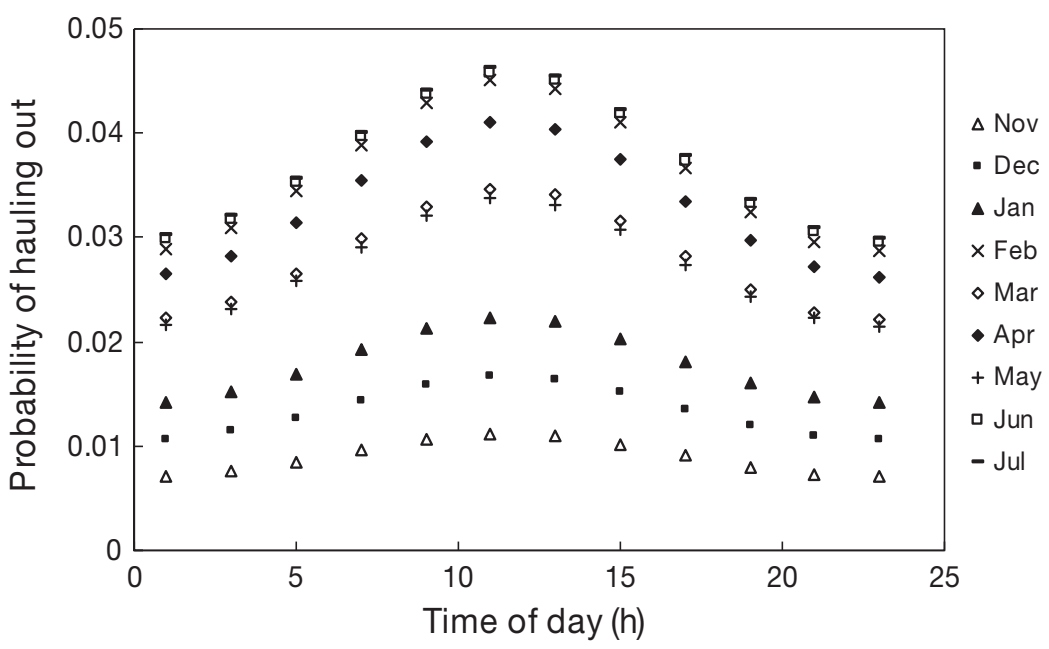

Fig. 5. Phoca vitulina. Estimated probability of hauling out as a function of time of day, by month 
included males and females of varying sizes, this assumption is likely to be realistic. The smallest animal was $120 \mathrm{~cm}$ in length, corresponding to an animal in its second year (age class 1) as estimated from available growth curves (Corpe 1996), and no seals weighing less than $50 \mathrm{~kg}$ (Table 1) were included. If animals in their first years of life consistently spend more or less time hauled-out than older animals, this would affect our estimates of abundance. To determine the approximate magnitude of possible bias in our abundance estimates, we assumed that the age structure in the Firth of Tay was comparable to that in the KattegatSkagerrak area prior to the 1988 phocine distemper virus (PDV) epizootic (Heide-Jørgensen et al. 1992), so that $31.2 \%$ of the population would be less than $2 \mathrm{yr}$ old (age class 0 or 1). Härkönen et al. (1999) found that the average re-sighting frequency of age class 1 was $60 \%$ greater than the average across all older age classes in the Kattegat-Skagerrak. Assuming that pups of the year behave the same as animals in age class 1 leads to population estimates that are $16 \%$ lower than those presented here. In the context of considering bias relative to precision, these corrected estimates still lie within our $95 \%$ confidence limits. There are no data to indicate whether this pattern of younger animals hauling out more frequently persists in months outside the breeding and moulting period.

Population estimates made at times when there were fewer than 10 animals tagged for the whole month were particularly variable. This suggests that inferences drawn from such small samples may be unreliable, and it may be advisable to apply this model structure only with larger sample sizes or if behaviour among individuals is less variable. Precision of estimates might also be increased by including weather condition covariates in the GLMM. Rainfall, air temperature and wind had a weak effect on haul-out behaviour in northeast Scotland during summer (Grellier et al. 1996), and more extreme winter weather conditions might have a greater effect on haul-out behaviour.

The framework presented here is equally applicable to other central place foragers, particularly marine predators that are tied to land for a period of their life cycle. Telemetry data for a species from each region of interest may be required because the behaviour of animals cannot be assumed to be consistent between regions. Although there was only a small difference in haul-out proportion found between our study and others on harbour seals in the North Sea (Thompson et al. 1997, Ries et al. 1998), in a study of 6 haul-out sites on the coast of Washington and Oregon, USA, Huber et al. (2001) concluded that regional correction factors were needed. In particular, distance between foraging areas and a haul-out site is likely to influence the proportion of time spent at sea. Moreover, population monitoring over longer, interannual and decadal time scales is likely to require further telemetry data, because the proportion of time spent foraging may respond to environmental changes such as changes in prey distribution (Thompson et al. 2001).

Acknowledgements. Many people helped with fieldwork; thanks are due in particular to K. Grellier and M. Cox for help with counts and S.E.W. Moss for persevering to devise ways to catch seals. Thanks to M. Lonergan for statistical advice. R.J.S. was supported by a National Environment Research Council (NERC) studentship. Thanks to P.M. Thompson for comments on earlier drafts of the manuscript.

\section{LITERATURE CITED}

Baker JR, Fedak MA, Anderson SS, Arnbom T, Baker R (1990) Use of a tiletamine-zolazepam mixture to immobilise wild grey seals and southern elephant seals. Vet Rec 126:75-77

Breed GA, Bowen WD, McMillan JI, Leonard ML (2006) Sexual segregation of seasonal foraging habitats in a nonmigratory marine mammal. Proc R Soc Lond B Biol Sci 273: 2319-2326

Brown EG, Pierce GJ (1998) Monthly variation in the diet of harbour seals in inshore waters along the southeast Shetland (UK) coastline. Mar Ecol Prog Ser 167:275-289

Corpe H (1996) The behavioural ecology of young harbour seals in the Moray Firth, NE Scotland. PhD thesis, University of Aberdeen

DeMaster DP, Fowler CW, Perry SL, Richlen MF (2001) Predation and competition: the impact of fisheries on marinemammal populations over the next one hundred years. J Mammal 82:641-651

Duck C, Thompson D (2003) The status of British common seal populations. Briefing paper for the Special Committee for Seals 2003. Sea Mammal Research Unit, University of St Andrews, St Andrews

Fedak M, Andreson S, Curry M (1983) Attachment of a radio tag to the fur of seals. J Zool (Lond) 200:298-300

Grellier K, Thompson PM, Corpe HM (1996) The effect of weather conditions on harbour seal (Phoca vitulina) haulout behaviour in the Moray Firth, N.E. Scotland. Can J Zool 74:1806-1811

Guinet C, Dubroca L, Lea MA, Goldsworthy S and others (2001) Spatial distribution of foraging in female Antarctic fur seals Arctocephalus gazella in relation to oceanographic variables: a scale-dependent approach using geographic information systems. Mar Ecol Prog Ser 219: 251-264

Härkönen T, Harding KC, Lunneryd SG (1999) Age- and sexspecific behaviour in harbour seals leads to biased estimates of vital population parameters. J Appl Ecol 36: $825-841$

Harwood J, Croxall J (1988) The assessment of competition between seals and commercial fisheries in the North Sea and the Atlantic. Mar Mamm Sci 4:13-33

> Heath MR (2005) Changes in the structure and function of the North Sea fish foodweb, 1973-2000, and the impacts of fishing and climate. ICES J Mar Sci 62:847-868

Heide-Jørgensen M, Härkönen T, Åberg P (1992) Long-term effects of epizootic in harbour seals in the KattegatSkagerrak and adjacent areas. Ambio 21:511-516

Huber H, Jeffries S, Brown R, DeLong R, VanBlaricom G 
(2001) Correcting aerial survey counts of harbour seals (Phoca vitulina richardsi) in Washington and Oregon. Mar Mamm Sci 17:276-293

Jefferies S, Brown R, Harvey J (1993) Techniques for capturing, handling and marking harbour seals. Aquat Mamm 19:21-26

Lonergan M, Duck CD, Thompson D, Mackey BL, Cunningham L, Boyd IL (2007) Using sparse survey data to investigate the declining abundance of British harbour seals. J Zool (Lond) 271:261-269

McConnell B, Chambers C, Nicholas K, Fedak M (1992) Satellite tracking of grey seals (Halichoerus grypus). J Zool (Lond) 226:271-282

McConnell BJ, Fedak MA, Lovell P, Hammond PS (1999) Movements and foraging areas of grey seals in the North Sea. J Appl Ecol 36:573-590

Myers RA, Baum JK, Shepard TD, Powers SP, Peterson CH (2007) Cascading effects of the loss of apex predatory sharks from a coastal ocean. Science 315:1846-1850

Prime JH, Hammond PS (1990) The diet of grey seals from the south-western North Sea assessed from analyses of hard parts found in faeces. J Appl Ecol 27:435-447

Ries EH, Hiby AR, Reijnders PJH (1998) Maximum likelihood population size estimation of harbour seals in the Dutch Wadden Sea based on a mark-recapture experiment. J Appl Ecol 35:332-339

Schneider DC, Payne PM (1983) Factors affecting haul-out of harbor seals at a site in southeastern Massachusetts. J Mammal 64:518-520

Sharples RJ (2005). Ecology of harbour seals in southeastern Scotland. PhD thesis, University of St Andrews

Simpkins MA, Withrow DE, Cesarone JC, Boveng PL (2003) Stability in the proportion of harbour seals hauled out under locally ideal conditions. Mar Mamm Sci 19:791-805

Editorial responsibility: Matthias Seaman, Oldendorf/Luhe, Germany
Springer AM, Estes JA, van Villet GB, Williams TM and others (2003) Sequential megafaunal collapse in the North Pacific Ocean: an ongoing legacy of industrial whaling? Proc Natl Acad Sci USA 100:12223-12228

Thompson PM, Harwood JH (1990) Methods for estimating the population-size of common seals, Phoca vitulina. J Appl Ecol 27:924-938

Thompson PM, Rothery P (1987) Age and sex differences in the timing of the moult in the common seal, Phoca vitulina. J Zool (Lond) 212:597-603

> Thompson PM, Fedak MA, McConnell BJ, Nicholas KS (1989) Seasonal and sex-related variation in the activity patterns of common seals (Phoca vitulina). J Appl Ecol 26: 521-535

Thompson PM, Tollit DJ, Wood D, Corpe H, Hammond PS, Mackay A (1997) Estimating harbour seal abundance and status in an estuarine environment. J Appl Ecol 34:43-52

> Thompson PM, Parijs S, Kovacs K (2001) Local declines in the abundance of harbour seals: implications for the designation and monitoring of protected areas. J Appl Ecol 38: $117-125$

> Thompson D, Lonergan M, Duck C (2005) Population dynamics of harbour seals Phoca vitulina in England: monitoring growth and catastrophic declines. J Appl Ecol 42:638-648

> Vincent C, McConnell BJ, Ridoux V, Fedak MA (2002) Assessment of Argos location accuracy from satellite tags deployed on captive grey seals. Mar Mamm Sci 18: 156-166

Watts P (1992) Thermal constraints on hauling out by harbour seals (Phoca vitulina). Can J Zool 70: 553-560

Wood S (2006). Generalized additive models: an introduction with R. Chapman and Hall/CRC Press, London

Yodzis P (2001) Must top predators be culled for the sake of fisheries? Trends Ecol Evol 16:78-84

Submitted: August 16, 2007; Accepted: November 17, 2008 Proofs received from author(s): March 9, 2009 